\title{
Las consecuencias de la sentencia Artavia Murillo en el Perú y el concebido
}

The consequences of the Artavia Murillo's sentence in Peru and the conceived child

DOI: 10.33539/consensus.2019.v24n2.2324

María Isabel Suárez Gómez ${ }^{1}$

\begin{abstract}
RESUMEN
La sentencia emitida por la Corte Interamericana de Derechos Humanos (Corte IDH), en el proceso seguido por Artavia Murillo y otros contra el Estado de Costa Rica, ya ha empezado a tener consecuencias jurídicas en el Perú, en relación con el derecho a la vida del concebido. En efecto, la citada sentencia ha sido materia de pronunciamientos jurisdiccionales en el Perú, los cuales señalan que la misma debe aplicarse, sin considerar que el criterio adoptado sobre el inicio del derecho a la vida del concebido, origina el desconocimiento de sus primeros días de existencia y, en consecuencia, contraviene la Constitución.

Los casos que se encuentran aún en discusión en sede judicial, se refieren a temas controversiales como el anticonceptivo oral de emergencia y el aborto terapéutico, los cuales no pueden ser considerados derechos sexuales y reproductivos, cuando se atenta contra la vida del más indefenso de los sujetos de derecho: el concebido.
\end{abstract}

\section{Palabras clave}

Concebido, derecho a la vida, aborto terapéutico, anticonceptivo oral de emergencia, sentencia

\section{ABSTRACT}

The sentence issued by the Inter-American Court of Human Rights (IN/A Court HR), in the proceeding followed by Artavia Murillo and others against the State of Costa Rica, has already legal consequences in Peru, corresponding to the right to life of conceived child. Indeed, the aforementioned sentence has been the subject of jurisdictional pronouncements in Peru, which indicate that it must apply, without considering that the criterion taken on the beginning of the right to life of the conceived child, originates the ignorance of the early days of his or her existence and, therefore, contravenes the Constitution.

The cases, which are still in discussion in court, refer to controversial issues such as emergency oral contraception and therapeutic abortion, which cannot be considered sexual and reproductive rights, when the life of the most defenseless subjects of the law is threatened: the conceived child.

\section{Keywords}

Conceived child, right to life, therapeutic abortion, emergency oral contraception, sentence

1 Abogada. Grado Académico de Maestro en Gobierno y Gestión Pública. Candidata al Grado Académico de Maestro en Derecho Civil por la USMP. Diplomada por la Universidad de Salamanca. Presidenta de la Comisión de Estudio de Reforma del Estado del Colegio de Abogados de Lima. 


\section{INTRODUCCIÓN}

Actualmente, se encuentran en discusión en el Poder Judicial temas que son materia de gran debate a nivel nacional, como son el anticonceptivo oral de emergencia y el aborto terapéutico; por esta razón, se requiere que los pronunciamientos emitidos se realicen de acuerdo con lo dispuesto por la normatividad constitucional y legal vigentes, teniendo en cuenta que ellas generarán consecuencias jurídicas profundas en nuestra sociedad.

En los procesos, en los cuales ya existe sentencia, se ha considerado como elemento de análisis la sentencia expedida por la Corte Interamericana de Derechos Humanos, en el caso Artavia Murillo contra el Estado de Costa Rica (Corte IDH, 2012), la cual realiza una interpretación diferente del propio texto de la Convención Americana de Derechos Humanos y considera que el inicio de la vida del concebido se origina cuando el embrión se implanta en el útero de la mujer. Este hecho jurídico es diferente al que reconoce el Perú, el cual establece que la vida se inicia con la concepción, es decir, cuando el óvulo es fecundado por el espermatozoide.

La incorrecta interpretación de la jerarquía de las normas de los jueces de primera instancia es la que ha originado el inadecuado análisis que -se espera- pueda ser corregida por el propio Poder Judicial en las instancias superiores; porque los pronunciamientos pueden conllevar a que se realicen modificaciones legales e incluso constitucionales, sin tener en cuenta que la vida se inicia desde el mismo instante que existe un nuevo ser, a quien el Estado está obligado a proteger.

\section{1.- El proceso Artavia Murillo y la nueva interpretación de la Convención Americana de Derechos Humanos}

El proceso se inicia con una petición presentada por Artavia Murillo y otros actores, ante la Comisión Interamericana de Derechos Humanos (CIDH), la misma que sometió a consideración de la Corte Interamericana de Derechos Humanos (Corte IDH, 2012) su pedido, por la violación de los derechos humanos en que habría incurrido Costa Rica, al disponer la prohibición general de la fecundación in vitro (FIV), derivada de una decisión emitida el 15 de marzo de 2000, por la Sala Constitucional de la Corte Suprema de Justicia, que declaró inconstitucional el Decreto Ejecutivo N. ${ }^{\circ} 24029-\mathrm{S}$, del 03 de febrero de 1995, emitido por el Ministerio de Salud de Costa Rica que autorizaba la práctica de la FIV y regulaba las técnicas de reproducción asistida entre cónyuges.

Los fundamentos expuestos en la petición consistían en que la decisión de la Corte Suprema constituía una injerencia arbitraria en los derechos a la vida privada y familiar y a formar una familia, así como una violación del derecho a la igualdad de las víctimas, por cuanto el Estado les impidió el acceso a un tratamiento que les hubiera permitido superar su situación de desventaja respecto de la posibilidad de tener hijos biológicos, señalando además que ese hecho habría tenido un impacto desproporcionado en las mujeres.

El 28 de noviembre de 2012, la Corte IDH señaló la responsabilidad de Costa Rica indicando:

2. El Estado debe adoptar, con la mayor celeridad posible, las medidas apropiadas para que quede sin efecto la prohibición de practicar la FIV y 
para que las personas que deseen hacer uso de dicha técnica de reproducción asistida puedan hacerlo sin encontrar impedimentos al ejercicio de los derechos que fueron encontrados vulnerados en la presente Sentencia. (p. 114)

De esta forma se pronunció por la petición formulada por los solicitantes, pero además, la sentencia realiza una interpretación del artículo 4.1 de la Convención Americana de Derechos Humanos, al establecer en su Fundamento 264 lo siguiente:

El embrión no puede ser entendido como persona para efectos del artículo 4.1 de la Convención Americana. ... la Corte concluyó que la "concepción” en el sentido del artículo 4.1 tiene lugar desde el momento en que el embrión se implanta en el útero, razón por la cual antes de este evento no habría lugar a la aplicación del artículo 4 de la Convención. (p. 83)

Menciona que la expresión "en general" que señala el artículo 4.1, referida a la protección del derecho a la vida, no debe entenderse de manera absoluta sino de forma gradual, debido a que no constituye un deber absoluto e incondicional, sino que implica entender la procedencia de excepciones a la regla general.

Con lo cual se advierte que la sentencia pretende modificar el concepto del inicio de la vida del concebido, que se encuentra reconocido en el artículo 4.1 de la Convención Americana (1969), que señala lo siguiente:

Artículo 4.- Derecho a la vida

1. Toda persona tiene derecho a que se respete su vida. Este derecho estará protegido por la ley y, en general, a partir del momento de la concepción. Nadie puede ser privado de la vida arbitrariamente. (p. 2)

De esta forma, se puede apreciar que la interpretación del artículo 4.1 de la Convención que realiza la sentencia no resulta ser "pro homine" o de mayor valor de los derechos fundamentales, por cuanto se pretende "retardar" el reconocimiento del inicio de vida del concebido, desconociendo sus primeros días de existencia.

La sentencia señala en su fundamento 186 , que la fecundación constituye el primer momento de la vida del concebido, siendo el segundo momento, el de la anidación. No obstante ello, indica que la vida del concebido se inicia cuando la nueva célula, se implanta en el útero materno, tal como se aprecia a continuación.

Fundamento 186.-

Al respecto, la Corte resalta que la prueba científica concuerda en diferenciar dos momentos complementarios y esenciales en el desarrollo embrionario:

- La fecundación y

- La implantación.

El Tribunal observa que solo al cumplirse el segundo momento se cierra el ciclo que permite entender que existe la concepción. ...

El Tribunal constata que, si bien al ser fecundado el óvulo se da paso a una célula diferente y con la información genética suficiente para el posible desarrollo de un "ser humano", lo 
cierto es que si dicho embrión no se implanta en el cuerpo de la mujer sus posibilidades de desarrollo son nulas. Si un embrión nunca lograra implantarse en el útero, no podría desarrollarse pues no recibiría los nutrientes necesarios, ni estaría en un ambiente adecuado para su desarrollo. (p. 60)

De esta forma, se puede advertir que el razonamiento que se encuentra en esta sentencia no resulta jurídicamente lógico, debido a que señala dos momentos para la constitución del derecho a la vida del concebido, pero solo reconoce su existencia, cuando se cumple el segundo momento. Por lo que pareciera que al momento de realizar el desarrollo de la sentencia, la misma se efectúa de manera lógica, pero cuando le corresponde llegar a la conclusión, lo realiza sin considerar el hecho referido a que el traslado del embrión hasta el útero materno debe seguir un proceso hasta llegar a anidarse.

El reconocimiento legal de la implantación como el inicio de la vida del concebido, origina la negación de su existencia real y concreta en sus primeros días de vida, lo cual podría interpretarse que al "no existir vida", se pudiera permitir y legalizar este hecho, evitando cualquier tipo de sanción punible, cuando una mujer decide terminar con la vida del concebido en su etapa inicial de concepción.

\section{2.- Aplicación de la Sentencia Artavia Murillo en el Perú}

Frente a dicho pronunciamiento jurisdiccional internacional -que realiza una interpretación al texto de la Convención Americana- lo que corresponde es establecer si esta sentencia resulta aplicable al Perú.

Para ello, es necesario mencionar que la Convención Americana de Derechos Humanos fue ratificada por el Perú el 07 de diciembre de 1978, aceptando la competencia de la Corte y de la Comisión el 21 de enero de 1981.

Siendo ello así, corresponde establecer qué indica la propia Convención Americana (1969) sobre las decisiones de la Corte, para los Estados que aceptaron su competencia. Así tenemos que el artículo 68 señala lo siguiente: "Los Estados Partes en la Convención se comprometen a cumplir la decisión de la Corte en todo caso en que sean partes" (p.20).

La norma citada permite entender que cualquier pronunciamiento derivado de un proceso, emitido por la Corte Interamericana de Derechos Humanos, corresponde que sea cumplido por el Estado que forma parte de dicho proceso. En ningún momento hace referencia que sea de obligatorio cumplimiento para todos los Estados que aceptaron la competencia de la Corte y de la Convención.

En tal sentido, el pronunciamiento emitido por la Corte IDH, en el proceso seguido por Artavia Murillo, contra Costa Rica, corresponde que sea cumplido por ese Estado y no tiene el carácter vinculante, para el resto de Estados, dentro de los cuales se encuentra el Perú, para acatar lo establecido en el citado pronunciamiento, por parte de los órganos jurisdiccionales peruanos.

A ello se debe agregar que la propia Convención Americana (1969) establece 
cómo deben ser interpretadas sus propias normas, tal como lo indica el literal b) del artículo 29, que señala lo siguiente:

Artículo 29.- Normas de interpretación Ninguna disposición de la presente Convención puede ser interpretada en el sentido de:

b) Limitar el goce y ejercicio de cualquier derecho o libertad que pueda estar reconocido de acuerdo con las leyes de cualquiera de los Estados Partes o de acuerdo con otra convención en que sea parte uno de dichos Estados. (p. 11)

Esta norma, que tiene el carácter de imperativa, es la que considera el Principio Pro Homine y establece en sus propias disposiciones, que no se pueden restringir derechos o libertades que se encuentran reconocidos en los textos legales de cada país que ha ratificado su contenido; esto significa que, en el caso del Perú, nuestro país no debe interpretar los alcances de la Convención si esta reconoce derechos menores a los que establece nuestra legislación nacional.

\section{3.- Pronunciamientos jurisdiccionales en el Perú}

\section{1.- El proceso judicial sobre el Anticonceptivo Oral de Emergencia}

Con los argumentos antes expuestos, corresponde analizar la sentencia emitida el 02 de julio de 2019 (resolución 47), por el Juez del Primer Juzgado Especializado en lo Constitucional de la Corte de Lima (2019a), referida a la demanda interpuesta por Violeta Cristina Gómez Hinostroza, contra el Ministerio de Salud y la ONG
"Acción de Lucha Anticorrupción Sin Componenda (Expediente N. ${ }^{\circ}$ 305412014), sobre el proceso de amparo respecto al Anticonceptivo Oral de Emergencia. En dicha sentencia, el juez nacional consideró que la sentencia expedida por la Corte IDH resulta vinculante para el Estado peruano, conforme se aprecia de los fundamentos décimo y decimotercero que indican lo siguiente:

\section{Décimo.- ...}

Las obligaciones relativas a la interpretación de los derechos constitucionales no sólo se extiendan al contenido normativo de la Convención strictu sensu, sino a la interpretación que de ella realiza la Corte Interamericana de Derechos Humanos a través de sus decisiones (sentencias, opiniones consultivas, medidas provisionales, supervisiones de sentencias). En ese sentido, el artículo V del Título Preliminar del Código Procesal Constitucional, establece ... (p. 13)

Para el Juez, los derechos constitucionales deben interpretarse de acuerdo con la Convención, así como los pronunciamientos que emita la Corte IDH, señalando como sustento de su afirmación, lo establecido por el Código Procesal Constitucional (2004).

Este argumento lo vincula con el Fundamento decimotercero, cuando indica lo siguiente:

Sepuede apreciarque la vinculatoriedad de la sentencia Artavia Murillo, obliga a nuestro ordenamiento jurídico a adecuarse al canon convencionalidad, de conformidad con el artículo 55, a la Cuarta Disposición Final y 
Transitoria de la Constitución y a la propia línea interpretativa del Tribunal Constitucional. (Primer Juzgado Especializado en lo Constitucional de la Corte de Lima, 2019, p. 18)

Lo cierto es que la interpretación que realiza el juzgador es incorrecta, debido a que no existe obligación del Estado peruano para cumplir con lo establecido en la sentencia Artavia Murillo, por cuanto la misma reconoce derechos menores a los contemplados en la Constitución Política del Perú (1993), en lo referido al inicio de la vida del concebido.

Más aún cuando se advierte que no se puede pretender que se entienda que el Código Procesal Constitucional (2004) obligue a su cumplimiento, cuando este cuerpo normativo no guarda la correcta concordancia con nuestra Carta Magna, como se puede apreciar a en la tabla 1.

Tabla 1

Constitución Politica del Perú 1993 y Código Procesal Constitucional

\begin{tabular}{|c|c|}
\hline $\begin{array}{l}\text { Constitución Política del Perú } \\
1993\end{array}$ & $\begin{array}{c}\text { Código Procesal Constitucional } \\
\text { Ley N. }{ }^{\circ} 28237 \\
\text { Publicado en el Diario Oficial "El Peruano" el } \\
\text { lunes } 31 \text { de mayo de } 2004\end{array}$ \\
\hline $\begin{array}{l}\text { Disposiciones Finales y Transitoria } \\
\text { Cuarta.- } \\
\text { Interpretación de los derechos }\end{array}$ & $\begin{array}{c}\text { Título Preliminar } \\
\text { Artículo V.- } \\
\text { Interpretación de los Derechos Constitucionales }\end{array}$ \\
\hline $\begin{array}{l}\text { Las normas relativas a los derechos } \\
\text { y a las libertades que la Constitución } \\
\text { reconoce se interpretan de conformidad } \\
\text { con la Declaración Universal de Derechos } \\
\text { Humanos y con los Tratados y acuerdos } \\
\text { internacionales sobre las mismas materias } \\
\text { ratificados por el Perú. }\end{array}$ & $\begin{array}{l}\text { El contenido y alcances de los derechos } \\
\text { constitucionales protegidos por los procesos } \\
\text { reguladosenel presenteCódigo debeninterpretarse } \\
\text { de conformidad con la Declaración Universal de } \\
\text { Derechos Humanos, los tratados sobre derechos } \\
\text { humanos, así como de las decisiones adoptadas } \\
\text { por los tribunales internacionales sobre derechos } \\
\text { humanos constituidos según tratados de los que el } \\
\text { Perú es parte. }\end{array}$ \\
\hline
\end{tabular}

Elaboración propia basada en la Constitución Política del Perú (1993, p. 70) y el Código Procesal Constitucional (2004, p. 3).

Por lo que no se aprecia lo indicado por Abad (2018) para quien "el Código Procesal Constitucional tiene como límite el marco de lo establecido en la Constitución vigente", (pp.130-131), debido a que precisamente, el Código Procesal Constitucional se ha "excedido" al efectuar un añadido, como resultan ser los pronunciamientos emitidos por tribunales internacionales.
De esta forma, y de acuerdo con el artículo V del Título Preliminar del Código Procesal Constitucional, es que el juez constitucional ha considerado que la sentencia correspondiente al proceso Artavia Murillo deba ser analizada en el proceso sobre el anticonceptivo oral de emergencia, aplicando el control de convencionalidad, en relación con las normas emitidas por el Perú, cuando realmente no corresponde. 
Lafferriere y Tello (2015) consideran que el control de convencionalidad es una doctrina que, de modo análogo al control de constitucionalidad -que busca establecer la supremacía de la Constitución al interior del Estado

tiene por meta afianzar la hegemonía de los tratados de derechos humanos en aquellos países que lo han ratificado. Así, todo juez local y autoridad nacional debe considerar sus actos no solo a la luz del parámetro de constitucionalidad, sino también al de convencionalidad. (p. 194)

Se debe señalar, además, que la Cuarta Disposición Final y Transitoria de la Constitución Política, establece que su contenido, referido a la interpretación de los derechos, así como el de las libertades que ella reconoce, deben guardar concordancia con los siguientes instrumentos internacionales y que enumera taxativamente:

- Declaración Universal de los Derechos Humanos.

- Tratados.

- Acuerdos internacionales.

Con relación a la incorporación de los Tratados o convenios celebrados por el Perú, a nuestra legislación nacional, el Tribunal Constitucional (2006) ha señalado en la sentencia N. ${ }^{\circ}$ 0047-2004Al que se mantiene vigente y que no ha sido modificada por otro criterio posterior, sobre el rango normativo en materia de interpretación, efectuando una precisión sobre el artículo 55 y la Cuarta Disposición Final y Transitoria de la Constitución Política del Perú, señalando lo siguiente:
Como puede apreciarse, nuestro sistema de fuentes normativas reconoce que los tratados de derechos humanos sirven para interpretar los derechos y libertades reconocidos por la Constitución. Por tanto, tales tratados constituyen parámetro de constitucionalidad en materia de derechos y libertades. Estos tratados no sólo son incorporados a nuestro derecho nacional, conforme al artículo 55 de la Constitución sino que, además, por mandato de ella misma, son incorporados a través de la integración o recepción interpretativa (Fundamento Jurídico 22). (p.31)

Pero, además, dicha sentencia hace referencia al orden y jerarquía de la normatividad del Perú, teniendo en cuenta dos criterios rectores, denominados "Categorías y Grados", cuando señala en su Fundamento Jurídico 61, lo siguiente:

La pirámide jurídica nacional debe ser establecida en base a dos criterios rectores, a saber:

a) Las categorías

Son la expresión deun género normativo que ostenta una cualificación de su contenido y una condición preferente determinada por la Constitución o por sus normas reglamentarias. Ellas provienen de una especie normativa; es decir, aluden a un conjunto de normas de contenido y valor semejante $\mathrm{o}$ análogo (leyes, decretos, resoluciones, etc.).

b) Los grados

Son los que exponen una jerarquía existente entre las normas pertenecientes a una misma categoría. Tal es el caso de las resoluciones (en cuyo orden decreciente aparecen 
las resoluciones supremas, las resoluciones ministeriales, las resoluciones viceministeriales, etc.).

En nuestro ordenamiento, existen las siguientes categorías normativas y sus subsecuentes grados:

\section{Primera categoría}

Las normas constitucionales y las normas con rango constitucional

1.er grado: La Constitución.

2. ${ }^{\circ}$ grado: Leyes de reforma constitucional.

3.er grado: Tratados de derechos humanos.
Al respecto, cabe señalar que el artículo 206 de la Constitución es la norma que implícitamente establece la ubicación categorial de las denominadas leyes constitucionales. De allí su colocación gradativamente inferior en relación a la Constitución en sí misma ... (p. 59)

Esta sentencia menciona que nuestro ordenamiento cuenta con cinco Categorías Normativas, las cuales comprenden diferentes grados, conforme se aprecia en la figura 1 .

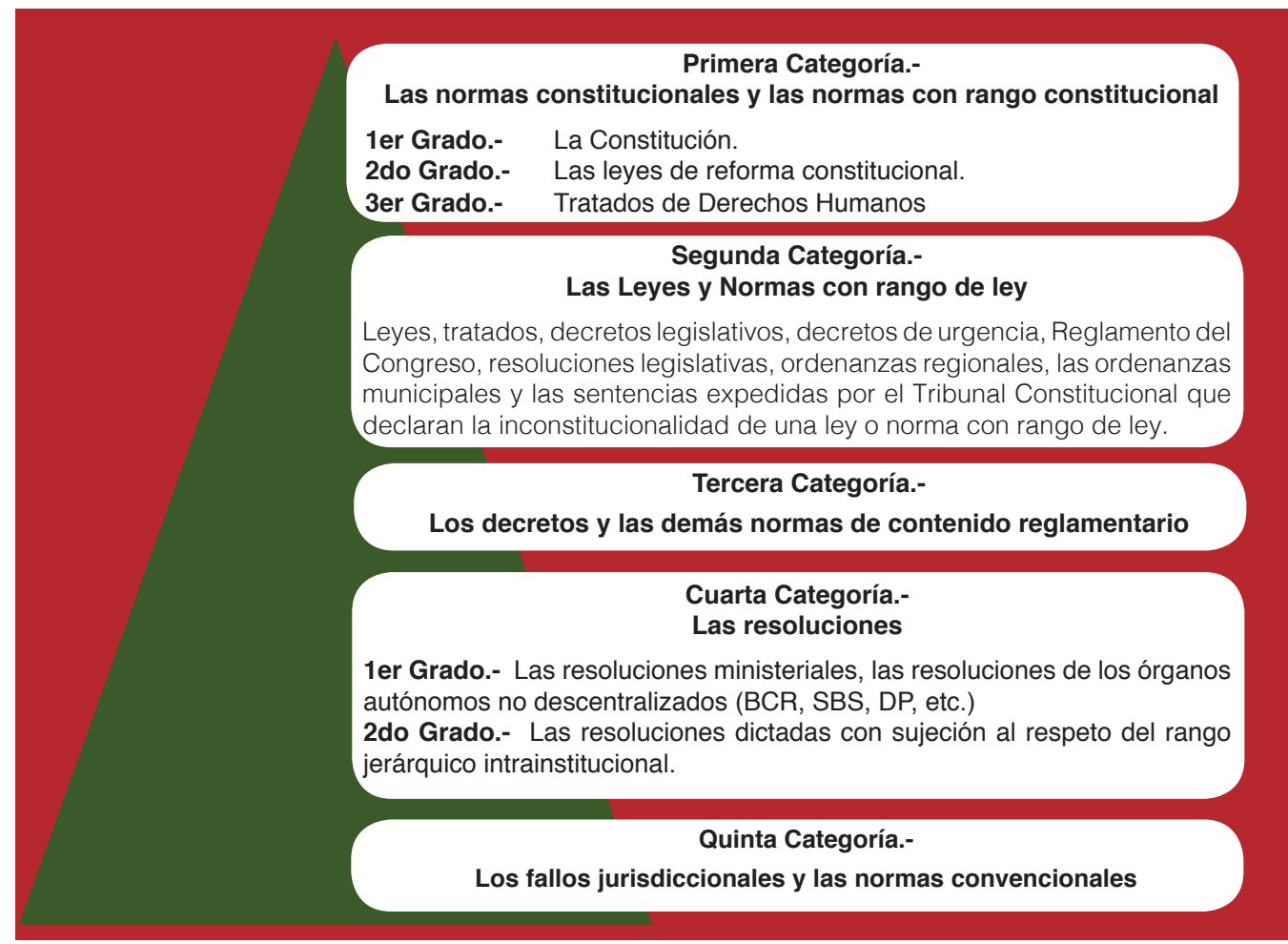

Figura 1. Categorías y Grados de la Jerarquía de normas en el Perú

Elaboración propia basada en Sentencia del Tribunal Constitucional 47-2004-AI.

La figura 1 permite apreciar que la Constitución Política del Perú, además de encontrarse en la Primera Categoría, se encuentra en el Primer Grado, es decir, tiene supremacía sobre el resto de normas que rigen nuestro régimen jurídico, por lo que, siendo ello así, la Constitución Política del Perú tiene preferencia, respecto de los Tratados sobre Derechos Humanos, que si bien se encuentran en la Primera Categoría, 
al igual que la Constitución, están situados en el Tercer Grado.

Como se ha indicado, los criterios y conceptos establecidos en esta sentencia, no han sido modificados o dejados sin efecto por otra sentencia posterior que establezca o determine los rangos y categorías de toda la normatividad que existe en el Perú, por lo que -en tal sentido- esta es la que debe ser utilizada para determinar el rango de los tratados sobre derechos humanos, en relación con la Constitución Política vigente, cuando se trate de analizar en los pronunciamientos jurisdiccionales.

Si bien es cierto que el Juez Constitucional ha mencionado algunas sentencias del Tribunal Constitucional, las mismas tienen la condición de referenciales, por cuanto no constituyen precedente vinculante $\mathrm{y}$, además, porque las mismas se encuentran comprendidas en la Quinta Categoría, de acuerdo con la figura 1.

De esta forma, se puede concluir que el pronunciamiento del Juez ha sido erróneo, debido a que ha utilizado una sentencia internacional la cual no es de obligatorio cumplimiento para el Perú, debido a que dicha sentencia señala menores derechos que el establecido por nuestro ordenamiento constitucional, respecto del derecho a la vida del concebido, pero, además, porque se pretende establecer, a través de su pronunciamiento, que el inicio de la vida del concebido se reconozca desde que es implantado en el útero, con lo cual se desconoce que la vida de este nuevo ser ya se está desarrollando y tiene derecho a la vida, desde el instante mismo de su concepción.

Pretender desconocer el derecho a la vida del concebido, significa, en realidad, negarle la existencia a un sujeto de derecho que, para el caso peruano, ya goza de protección y reconocimiento a nivel constitucional.

Como lo indica Fernández Sessarego (2005), ponente del Libro I del Código Civil Peruano de 1984:

El momento de la fusión de los núcleos del óvulo y del espermatozoide, científicamente se designa como singamia. La clave genética identifica al nuevo ser humano para toda la vida. En ella está dada, como se ha señalado, toda la información sobre lo que será la persona.... La vida dura hasta el momento de la muerte y está protegida a lo largo de todo este tiempo. Distinguimos, por tanto, la vida humana de la persona en el Derecho: la vida humana es la que acabamos de definir. La persona, a su turno, existe desde el nacimiento, pues, este hecho, produce determinadas consecuencias importantes en el aspecto de atribución de deberes al ser humano.... (pp. 4243)

Este es el análisis de las implicancias de la sentencia Artavia Murillo, en la sentencia sobre el anticonceptivo oral de emergencia, que tiene relación con el inicio del derecho a la vida del concebido, pero que no es el único proceso que se encuentra vigente en el Perú.

\section{2.- Los procesos judiciales sobre la Guía Técnica Nacional del Aborto Terapéutico}

Existe un proceso judicial, que guarda relación sobre la vida del concebido y que se encuentra referido a la Guía Técnica del aborto terapéutico, el cual se inicia con la demanda interpuesta por la ONG 
"Acción de Lucha Anticorrupción Sin Componenda", contra el Ministerio de Salud y la ONG Promsex, expediente 31583-2014, en el proceso constitucional de amparo, seguido ante el Primer Juzgado Especializado en lo Constitucional de Lima (2019b), es decir, ante el mismo Juzgado que conoció el caso anterior.

En este proceso, las pretensiones de la accionante se encuentran referidas a que se deje sin efecto la Guía Técnica Nacional del aborto terapéutico, por considerarla inconstitucional y exceder el contenido del artículo 119 del Código Penal (1991) -norma que describe la conducta denominada aborto terapéutico y que exime de sanción penal- $\mathrm{y}$, en consecuencia, se vuelva al estado anterior de las prácticas médicas que indica el Colegio Médico y la Federación Médica del Perú, referidas a salvar la vida del concebido y de la mujer gestante.

Conforme a lo expuesto por el Juez, la demanda interpuesta tiene por finalidad proteger el derecho a la vida del concebido, que como derecho fundamental de la persona humana obliga a su protección del Estado y, en tal sentido, la controversia consiste en determinar si la Guía Técnica del aborto terapéutico incide en el derecho fundamental de la vida del concebido. Es decir, el análisis se realiza ponderando un instrumento como es la Guía Técnica, frente al derecho a la vida.

Para desarrollar la sentencia, el Juez menciona los procesos interpuestos en el ámbito internacional contra el Estado peruano, por Noelia Karin Llantoy Huamán (Comité de Derechos Humanos de las Naciones Unidas [Comité DH], 2005) y Liz Margot Chalco Palacios, conocidos como K.L. y L.C. (ambas, al momento de ocurridos los hechos, eran menores de edad), al habérseles negado la realización del aborto terapéutico.

Sobre los casos citados, es necesario reseñar y precisar lo siguiente:

Karin Llantoy solicitó la realización del aborto terapéutico, por cuanto de acuerdo a la ecografía realizada, tendría un bebe anencefálico, quien nació, al cual amamantó y falleció a los pocos días. Por esta razón, interpuso una denuncia contra el Estado peruano, ante el Comité de Derechos Humanos de las Naciones Unidas (Comité DH, 2005) al no habérsele realizado el aborto terapéutico. En este proceso, el Estado peruano no ejerció su derecho de defensa, y el 24 de octubre de 2005, el Comité de DH emitió su dictamen mediante comunicación $\mathrm{N} .^{\circ}$ $1153 / 2003$, señalando que ella fue obligada a continuar su embarazo y se dispuso que el Estado peruano se encontraba en la obligación de proporcionarle un recurso efectivo, que incluyera una indemnización, pero, además, el de adoptar medidas para evitar que se cometan violaciones de derechos semejantes en el futuro (CCPR/C/85/1153/2003).

Posteriormente, y a nivel nacional, Karin Llantoy interpuso una demanda ante el Poder Judicial, contra el Ministerio de Salud y el Ministerio de Justicia y Derechos Humanos (Ministerio de Justicia, 2015), y fue durante el transcurso del proceso, que las partes conciliaron extrajudicialmente, correspondiendo al primer Ministerio el pago de una indemnización a su favor $y$, al segundo, la publicación de la sentencia del Comité de DH, en el diario oficial El Peruano. 
En cuanto a Liz Chalco, su situación fue diferente. Ella fue violentada sexualmente, originando que intentara suicidarse, lanzándose del techo de un edificio. No se le pudo operar debido a que se encontraba embarazada y cuando se produjo un aborto espontáneo y se le operó, no logró recuperarse. Por ello interpuso una denuncia contra el Estado peruano, y el 17 de octubre de 2011, el Comité de Naciones Unidas para la Eliminación de la Discriminación contra la Mujer (CEDAW, 2011) emitió su Dictamen, mediante Comunicación $\mathrm{N}^{\circ}{ }^{\circ}$ $22 / 2009$, por el que declaró responsable al Perú, recomendando se le indemnice por daños morales y materiales producidos y se le otorgue medidas de rehabilitación. Además señaló que el Perú debía:

a) Revisar su legislación con miras a establecer un mecanismo para el acceso efectivo al aborto terapéutico, en condiciones que protejan la salud física y mental de las mujeres e impidan que en el futuro se produzcan violaciones similares a las del presente caso...". (CEDAW/ C/50/D/22-2009, p. 9)

En este caso, Liz Chalco y el Ministerio de Salud conciliaron extrajudicialmente (Ministerio de Salud, 2015; Superintendencia Nacional de Salud, 2015).

Continuando con el análisis de la sentencia sobre la Guía Técnica del aborto terapéutico, el Juez, en su noveno considerando, señala que

... resulta fundamental establecer los estándares en materia internacional respecto a la vida en formación y la autonomía de la mujer en estado de embarazo, desarrollados por los diferentes instrumentos internacionales y sus respectivas instancias de interpretación, en consideración que, a la fecha de interposición de la demanda, no se tuvo en cuenta los distintos pronunciamientos que realizó la Corte Interamericana de
Derechos Humanos sobre este tema (caso Artavia Murillo vs Costa Rica "Fecundación In Vitro"). (p. 8)

El Juez, al realizar su análisis, se ciñe a las disposiciones que establece la Guía Técnica del aborto terapéutico (primer criterio de ponderación) y al contenido literal de la sentencia Artavia Murillo (segundo criterio de ponderación), sin tener en cuenta que no correspondía aplicar este segundo criterio, sino el pronunciamiento expedido por el Tribunal Constitucional (2009) en la sentencia N. ${ }^{\circ}$ 2005-2009-AI/TC, que se acoge a la teoría de la fecundación, pero, además, a la doctrina nacional, en la cual autores como Rubio, Eguiguren y Bernales (2018) señalan que la protección del concebido se realiza

desde el instante en que espermatozoide y óvulo forman el cigoto por su unión, ya que allí se ha configurado una realidad completamente distinta de las que existían previamente, esto es, el espermatozoide y el óvulo por separado. A partir de este momento, el concebido goza de los derechos constitucionales (p. 99).

Con lo cual se puede apreciar que esta definición guarda exacta correspondencia con la de Fernández Sessarego, quien es precisamente el ponente del Libro I del Código Civil, referido al derecho de las personas y el que mejor ha desarrollado el concepto del concebido; sin dejar de mencionar a Varsi (2017), para quien el concebido es entendido como:

Aquel ser humano que se encuentra en un estado de desarrollo biológico primario, sea in útero, estado gestional o ex útero, por implantarse o crioconservado.

Este estado es apreciado de una manera singular por el Derecho, otorgándole un trato especial, diferencial, propio para su situación biológica. El concebido no es un sujeto de derecho común, sino, a contrario sensu, es un sujeto de derecho sui géneris, especial y único. (p. 216) 
O como lo indica Espinoza (2014), “el concebido ... pese a que depende de la madre para su subsistencia, está genéticamente individualizado frente al ordenamiento jurídico y, como tal, se convierte en un centro de imputación de los derechos y los deberes que lo favorecen" (p. 73).

Otra consideración que no ha sido analizada por el Juez es la referida al hecho que la propia Guía Técnica, es una norma de carácter eminentemente procedimental del artículo 119 del Código Penal (1991) y ha sido expedida mediante una norma infralegal, como resulta ser la Resolución Ministerial N. ${ }^{\circ}$ 486-2014-MINSA, del 27 de junio de 2014 (Ministerio de Salud, 2014). Debiendo precisar que el artículo 119 del Código Penal, no reconoce al aborto terapéutico como un derecho de la mujer o un permiso a los médicos para realizarlo. Lo que señala es la despenalización, es decir, la ausencia de sanción por su realización, precisamente por lo singular de la situación, es decir, cuando es el único medio para salvar la vida o para evitar un mal grave y permanente en la salud de la mujer gestante, siendo estas situaciones de excepción las que originan que no se le castigue por impedir la continuación de la vida del concebido. Tal como lo indica Caro (2008), el aborto terapéutico constituye un estado de necesidad exculpante:

Si bien no cabe hacer una distinción de ambas vidas por su valor, porque la vida humana tanto dentro del vientre como fuera de él tiene el mismo valor constitucional, mereciendo por ello protección jurídica como derecho a la vida, sí es posible en cambio, levantar una excepción o un límite a ese derecho, pero sólo en función del contexto social concreto, donde la conducta practicada ejerce su fuerza comunicativa, en este caso, ceñido a la especial situación de necesidad. (p. 458)

Un segundo aspecto no analizado por el Juez Constitucional es el referido a establecer si la
Guía Técnica del aborto terapéutico expedida en el año 2014, emitida para estandarizar el procedimiento (en virtud de su condición de norma eminentemente procedimental) se está cumpliendo.

Por cuanto se entiende que la misma se expidió para salvar la vida o la salud de la mujer gestante y para tal fin, se ha establecido un procedimiento que se debe cumplir. El cumplimiento de la Guía Técnica se puede advertir solo de la información de las Historias Clínicas de los Hospitales, que son los instrumentos donde debe constar si el procedimiento establecido se está cumpliendo o no. Porque si el procedimiento no se cumpliera, significaría, al no considerar lo dispuesto por el Ministerio de Salud, quien es el que finalmente lo expidió, que no tendría sentido la vigencia de esta en el Perú.

Pero, además, porque significaría que al Ministerio de Salud, en su condición de ente Rector en Salud, solo se le estaría brindando información sobre el número de casos atendidos, pero no se le informaría cómo se estarían realizando los procedimientos, no solo en Lima, sino también en el ámbito nacional. Este aspecto es muy importante, para establecer si es útil el procedimiento de la Guía Técnica del aborto terapéutico.

En este proceso judicial, se declaró infundada la demanda, y, con el recurso de apelación interpuesto, se tiene por finalidad que el superior jerárquico conozca y revise el contenido de la sentencia

El otro proceso sobre el aborto terapéutico y que todavía no tiene sentencia, es la demanda de acción popular, correspondiente al expediente N. ${ }^{\circ}$ 58-2018 en el proceso seguido ante la Primera Sala Civil de la Corte Superior de Justicia de Lima, por la Asociación Centro de Estudios Jurídicos Santo Tomás Moro contra el Ministerio de Salud, para que se declare la inconstitucionalidad de la Resolución Ministerial N. ${ }^{\circ}$ 486-2014/ MINSA, norma que aprueba la Guía Técnica 
del aborto terapéutico, por cuanto la misma infracciona la Constitución Política de manera total, tanto por la forma, como por el fondo.

Menciona que es inconstitucional por cuanto no se encuadra en lo dispuesto la Ley 27444, Ley del Procedimiento Administrativo General que dispone que es requisito para la validez de todo acto administrativo que su contenido se ajuste a lo dispuesto en el ordenamiento jurídico, debiendo ser lícito, preciso, posible física y jurídicamente. Y además, porque vulnera la Constitución Política del Perú, en lo referente al derecho a la vida, a la política nacional de población paternidad y maternidad responsables, al derecho a la salud y a la política nacional de salud, así como lo establecido en la Ley General de Salud -Ley N. ${ }^{\circ}$ 26842, sobre el derecho a la vida del concebido, al respeto de la personalidad de toda persona, así como lo regulado en el artículo 17, que señala que ninguna persona puede actuar o ayudar en prácticas que signifiquen peligro, menoscabo o daño para la salud de terceros o de la población.

Como es un proceso de acción popular, la Sala Civil de la Corte Superior de Lima, actúa como primera instancia, y, como se ha mencionado, aún no tiene sentencia.

\section{CONCLUSIONES}

1. De acuerdo con la jerarquía de las normas de nuestro país, la Constitución Política tiene prevalencia sobre cualquier otra norma, sentencia o tratado que se integran a nuestra normativa.

2. La sentencia correspondiente al proceso Artavia Murillo contra Costa Rica, es un pronunciamiento jurisdiccional internacional, emitido por la Corte Interamericana de Derechos Humanos, que no tiene prevalencia sobre la Constitución Política del Perú.

3. El inicio del derecho de la vida del concebido en el Perú se efectúa desde que el óvulo es fecundado por el espermatozoide; en consecuencia, la interpretación que realiza la sentencia Artavia Murillo del artículo 4.1. de la Convención Americana de Derechos Humanos, la cual considera que la vida se inicia desde que el óvulo es anidado en el útero materno, no resulta aplicable para el Perú.

4. Las sentencias emitidas en el Perú, sobre el anticonceptivo oral de emergencia y la Guía Técnica del aborto terapéutico, no han realizado una adecuada ponderación sobre la jerarquía de las normas, dando preferencia a la sentencia Artavia Murillo, en relación con la Constitución Política del Perú. 


\section{REFERENCIAS}

Abad, S. (2018). Constitución y procesos constitucionales. Estudio introductorio, legislación, jurisprudencia e indices ( $7^{\mathrm{a}}$ ed.). Lima, Perú: Palestra Editores.

Caro, J. (2008). Sobre la relevancia del protocolo médico para la concreción del riesgo permitido en el aborto terapéutico. Ius Et Veritas, 18(36), 446-458.

Código Penal. (1991). Ministerio de Justicia. Lima.

Código Procesal Constitucional. (2004). Ley N. ${ }^{\circ} 28237$. Lima.

Comité de Derechos Humanos de las Naciones Unidas. (2005). Comunicación 1153-2003. Caso Karen Noelia Llantoy Huamán contra Perú; Dictamen del 24 de octubre de 2005. Suiza.

Comité de Naciones Unidas para la Eliminación de la Discriminación contra la MujerCEDAW. (2011). Comunicación 22-2009 (2011). T.P.F. (Representada por el Centro de Derechos Reproductivos y el Centro de Promoción y Defensa de los Derechos Sexuales y Reproductivos) contra Perú; Dictamen del 17 de octubre de 2011.

Constitución Política del Perú. (1993). Ministerio de Justicia. Lima.

Convención Americana sobre Derechos Humanos. (1969). Convención Americana de Derechos Humanos suscrita en la Conferencia especializada Interamericana sobre derechos humanos (B-32). San José de Costa Rica 7 al 22 de noviembre de 1969. Recuperado de https://www. oas.org/dil/esp/tratados_B-32_Convencion_Americana_sobre_Derechos_Humanos.pdf

Corte Interamericana de Derechos Humanos. (2012). Caso Artavia Murillo y otros Vs. Costa Rica. Sentencia de 28 de noviembre de 2012.

Espinoza, J. (2012). Derechos de las personas (6. ${ }^{\mathrm{a}}$ ed.). Lima: Grijley.

Fernández Sessarego, C. (2005). Tratamiento jurídico del concebido. En Libro homenaje a Mario Alzamora Valdez (pp. 42-43). Lima. Cultural Cuzco.

Lafferriere, J. y Tello, A. (2015). El diagnóstico genético preimplantatorio: de nuevo sobre los límites de Artavia Murillo. Foro Jurídico, 14, 194-205.

Ministerio de Justicia. (2015). Acta de Conciliación con Acuerdo Total Nro. 509-2015- CCG/ $S C$. Celebrado entre el Ministerio de Salud, el Ministerio de Justicia y Derechos Humanos y Karin Llantoy.

Ministerio de Salud. (2014). Resolución Ministerial N. ${ }^{\circ}$ 486-2014-MINSA del 27 de junio de 2014, por el cual se aprueba la Guía Técnica Nacional de Interrupción Voluntaria del Embarazo. Publicado en el Diario Oficial El Peruano.

Ministerio de Salud. (2015). Resolución Ministerial N. ${ }^{\circ}$ 852-2015/MINSA del 29 de diciembre de 2015. Se autorizó al Procurador Público y/o a la Procuraduría Pública Adjunta del Ministerio de Salud, a conciliar extrajudicialmente en representación del Ministerio de Salud.

Primer Juzgado Especializado en lo Constitucional de Lima. (2019a). Expediente N. ${ }^{\circ}$ 30541-2014-18-1801-JR-CI-01.

Primer Juzgado Especializado en lo Constitucional de Lima (2019b). Expediente N. ${ }^{\circ}$ 31583-2014-0-1801-JR-CI-01.

Primera Sala de Derecho Civil de Lima. Expediente N. ${ }^{\circ}$ 00058-2018-0-1801-SP-CI-01. 
Rubio, M., Eguiguren, F. y Bernales, E. (2017). Los Derechos Fundamentales en la Jurisprudencia del Tribunal Constitucional. Análisis de los Artículos 1, 2 y 3. (3.a Reimp.) Lima. Fondo Editorial de la Pontificia Universidad Católica del Perú.

Superintendencia Nacional de Salud. (2015). Acta de Conciliación con Acuerdo Total N. ${ }^{\circ} 83-$ 2015-CONC. Celebrado entre Liz Margot Chalco Palacios y el Ministerio de Salud.

Tribunal Constitucional del Perú (2006). Expediente N. ${ }^{\circ}$ 047-2004-AI/TC. 24 de julio de 2006.

Tribunal Constitucional del Perú (2009). Expediente N. ${ }^{\circ}$ 02005-2009-PA/TC. 16 de octubre de 2009.

Varsi,E. (2017). Clasificación del sujeto de derecho frente al avance de la genómicay la procreática. Acta bioethica, 23(2), 213-225. https://dx.doi.org/10.4067/S1726-569X2017000200213

Fecha de recepción: 28-10-2019

Fecha de aceptación: 29-11-2019 